\title{
Economics of production efficiency: Nutritional grouping of the lactating $\mathrm{cow}^{1}$
}

\author{
V. E. Cabrera ${ }^{2}$ and A. S. Kalantari \\ Department of Dairy Science, University of Wisconsin, Madison 53706
}

\section{ABSTRACT}

Nutritional grouping of lactating cows under total mixed ration (TMR) feeding systems has been discussed in the literature since 1970. Most studies have concluded that using multiple, more-homogeneous TMR feeding groups is economically beneficial because of either nutrient cost savings, improved productivity, or both. Nonetheless, no consensus has been formed around this technique nor has it been widely adopted. By using optimal criteria for grouping and more precise nutrient specifications of diets, the latest studies have reported a consistently greater income over feed cost (\$/cow per year) with multiple TMR groups compared with $1 \mathrm{TMR}(3 \mathrm{TMR}=\$ 46$ and $2 \mathrm{TMR}=\$ 21$ to $\$ 39)$. Critical factors that determine the economic value of nutritional grouping are: (1) criteria for grouping, (2) nutrient specifications of diets, (3) effects on milk production, (4) health and environmental benefits, (5) number, size, and frequency of grouping, and (6) additional costs and benefits. It has been documented that grouping cows according to their simultaneous nutritional requirements (a.k.a., cluster grouping) is optimal. Cluster grouping is superior to other methods, such as grouping according to days in milk, milk production, or production and body weight combined. However, the dairy industry still uses less-than-optimal grouping criteria. Using cluster grouping will enhance the positive economic effects of multiple TMR. In addition, nutrient specifications of diets for groups do not seem optimal either. Milk lead factors, which are only based on group average milk production, are used. Diets could, however, be formulated more precisely based on overall group nutrient requirements. Providing more precise diets should also be in favor of grouping eco-

Received May 21, 2015.

Accepted September 13, 2015.

${ }^{1}$ Presented as part of the Production Efficiency of the Dairy Cow Symposium at the ADSA-ASAS Joint Annual Meeting, Orlando, Florida, July 2015.

${ }^{2}$ Corresponding author: vcabrera@wisc.edu

nomics. Furthermore, an area that requires more attention is the potential negative effect of grouping on the milk production of moved cows because of either or both social interactions or diet concentration changes. Although the literature is inconclusive on this subject matter, the latest studies indicate that multiple TMR groups economically outperform 1 TMR, even after considering plausible potential milk losses when grouping. Moreover, additional positive effects of nutritional grouping of improved herd health and environmental stewardship should be translated into economic benefits. Finally, additional costs of management, labor, facilities, and equipment required for grouping are farm specific. The few studies that have integrated these factors in their analyses found that multiple TMR groups would still be economically superior to $1 \mathrm{TMR}$.

Key words: diets, feeding systems, nutritional grouping, production efficiency

\section{INTRODUCTION}

Grouping lactating cows for nutritional purposes, also referred as nutritional grouping, is a herd management practice that provides different diets to different groups of lactating cows to better fulfill their nutrient requirements. Hence, nutritional grouping can be beneficial by saving feed costs, improving productivity, improving herd health, and decreasing nutrient emissions to the environment. The notion of grouping lactating cows for nutritional purposes under TMR feeding systems has been discussed in the literature for several decades (Smith and Coppock, 1974; Smith et al., 1978; McGilliard et al., 1983). It is intuitive to assume that multiple, more-homogeneous TMR feeding groups - as opposed to only feeding 1 TMR diet for all cows - improves economic efficiency because of either nutrient cost savings, improved productivity, or both (i.e., diets are closer to cow requirements). Multiple TMR diets for lactating cows could promote higher profitability and less nutrient waste even though it could require more capital management and labor cost (VandeHaar, 2011). Nutritional grouping of lactating cows promotes optimal body condition and health (Allen, 2009), an additional 
advantage that could translate into economic benefits. Allen $(2000 ; 2009)$ contends that the control of feed intake changes as lactation progresses from a function of rumen fill to a satiety signal controlled by the liver (hepatic oxidation theory). Consequently, manipulation of diets through nutritional grouping strategies maintain intake and likely improve productivity and income over feed costs. Grouping decreases within-group and increases across-group variation of diets' nutrient density, reducing competition at the feed bunk (Grant and Albright, 2001). It could also be argued that lack of nutritional grouping is an important factor in culling decisions. Cows culled in a single TMR feeding system are not the least efficient, productive, or profitable, but those that could not adapt to the less than optimal management of a single TMR diet (VandeHaar, 2011). Single TMR systems do not allow for an optimal allocation of ingredients, nutrients, or additives to the cows that need them and would benefit the most from them. For example, supplements high in RUP or fat may benefit early lactation, but not later lactation cows. However, these nutrients are usually provided equally to all cows when no nutritional groups exist (VandeHaar, 2011). Although it has been clearly established that different diets are warranted for dry and early postpartum cows (Grant and Albright, 2001), neither a consensus nor a wide or proper adoption of multiple TMR feeding strategies has occurred for lactating cows (Jordan and Fourdraine, 1993; Jonker et al., 2002; Contreras-Govea et al., 2015). The purpose of this review paper is to discuss the value of multiple TMR feeding compared with 1 TMR feeding for lactating cows with a focus on dairy farm economic efficiency.

\section{REVIEW AND DISCUSSION}

\section{Economic Effects of Nutritional Grouping}

Economic results from a series of studies from the 1970s through the 1990s were inconclusive about the economic value of multiple TMR grouping strategies. Whereas a study reported that 1 TMR was superior to 2 TMR (Cassel et al., 1984), others found no differences (Davenport and Rakes, 1973; Everson et al., 1976; Wilk et al., 1978), small differences in favor of multiple TMR (Kroll et al., 1987), and substantial differences of multiple TMR (Smith and Coppock, 1974; Smith et al., 1978). Smith (1976) and Coppock et al. (1981) concluded that savings of feed costs with 2 TMR would economically outweigh its lower productivity and that, as a result, multiple TMR feeding systems would be preferred because they would provide greater income over feed cost (IOFC).

Published studies that reported on the economics of nutritional grouping strategies are listed in Table 1. Although not all values in Table 1 are directly comparable, data show an economic benefit obtained through multiple TMR feeding systems.

Smith et al. (1978) found an IOFC advantage of \$30/ cow per year for 2 TMR compared with 1 TMR. Smith et al. (1978) provided either 1 diet for the entire lactation (TMR $1=56 \%$ corn silage and $44 \%$ concentrate in DM) or 2 diets (same as TMR 1 for early and highproducing cows and TMR $2=84 \%$ corn silage and $16 \%$ concentrate in DM for lower-producing cows). Overall, even though grouped cows produced $0.6 \mathrm{~kg} / \mathrm{d}$ less milk and consumed $1.6 \mathrm{~kg} / \mathrm{d}$ more corn silage, they also con-

Table 1. Research evaluating the economics of nutritional grouping of lactating dairy cattle

\begin{tabular}{|c|c|c|c|c|c|}
\hline Reference & $\begin{array}{l}\text { Type of } \\
\text { study }^{1}\end{array}$ & $\begin{array}{l}\text { Grouping } \\
\text { criteria }^{2}\end{array}$ & \multicolumn{3}{|c|}{ Difference in income over feed cost $(\$ /$ cow per year $)$} \\
\hline Smith et al., 1978 & $\mathrm{~F}$ & DIM & & & 30 \\
\hline Williams and Oltenacu, 1992 & $\mathrm{~S}$ & $\mathrm{C}$ & \multicolumn{3}{|c|}{31} \\
\hline Østergaard et al., 1996 & $\mathrm{~S}$ & $\mathrm{DIM} / \mathrm{M}$ & \multicolumn{3}{|c|}{$3 \mathrm{TMR}>2 \mathrm{TMR}>1 \mathrm{TMR}$ net revenue ${ }^{4}$} \\
\hline St-Pierre and Thraen, 1999 & $\mathrm{~S}$ & & \multicolumn{2}{|c|}{33} & $\begin{array}{l}44 \\
38\end{array}$ \\
\hline Kalantari et al., $2015^{5}$ & $\mathrm{~S}$ & $\mathrm{C}$ & 46 & 8 & 39 \\
\hline
\end{tabular}


sumed $2.3 \mathrm{~kg} / \mathrm{d}$ less concentrates, which equated to a net IOFC gain of $\$ 30 /$ cow per year. Those cows that switched from TMR 1 to TMR 2 lost $2 \mathrm{~kg} /$ cow per day of milk production during at least 5 wk. Afterward, differences in production were $1 \mathrm{~kg} / \mathrm{d}$ or less by wk 13 for primiparous cows and $1 \mathrm{~kg} / \mathrm{d}$ or more by wk 15 for multiparous cows. Smith et al. (1978) concluded that the deleterious effects of feed and group changes on milk yield are of greater magnitude and longer duration in multiparous cows.

Previously, Smith and Coppock (1974) reported an advantage of $\$ 60 /$ cow per year of IOFC for the 2 TMR feeding group treatment, even though these cows produced $120 \mathrm{~kg}$ of FCM/cow less per year. Smith (1976) speculated that more feeding groups would result in greater feed efficiencies and an increased IOFC, although feeding groups should be economically evaluated along with additional labor requirements, housing, and handling facilities. Studies in the 1970s (Smith and Coppock, 1974; Smith, 1976; Smith et al., 1978) that grouped cows by a combination of DIM, milk yield threshold, and pen overcrowding changed the diet whenever cows were moved to a different group. This strategy resulted in a sudden, rather high $(1-2 \mathrm{~kg} / \mathrm{cow}$ per day) and persistent milk loss (13 to $37 \mathrm{wk})$. This was also documented by Moseley et al. (1976), who reported a milk yield decrease for the entire evaluated period of $3 \mathrm{wk}$ of $19.0,28.1,26.0$, and $29.1 \%$ when forage in the ration increased from 40 to $60,75,80$, and $95 \%$, respectively. The most significant change in Moseley et al. (1976) from a low-forage (40\%; $1.91 \mathrm{Mcal}$ of $\mathrm{NE}_{\mathrm{L}} / \mathrm{kg}$ of $\left.\mathrm{DM}\right)$ to a high-forage $(95 \% ; 1.71$ Mcal of $\mathrm{NE}_{\mathrm{L}} / \mathrm{kg}$ of $\mathrm{DM}$ ) diet resulted in $2.5 \mathrm{~kg} / \mathrm{cow}$ per day less milk yield.

Results from Coppock (1977), Smith et al. (1978), and Coppock et al. (1981) reported an economic disadvantage in the multiple group approach. These studies had fixed diets and maintained the 1 TMR diet as one of the diets in the 2 TMR strategy.

Cassel et al. (1984) also compared 1 TMR versus 2 TMR diets, but, unlike Smith et al. (1978) and Smith and Coppock (1974), they did not repeat the 1 TMR diet as one of the 2 TMR diets. Instead, their 2 TMR strategy used a higher and lower level of concentrate than the sole 1 TMR strategy. They did not find statistical differences for the $\mathrm{NE}_{\mathrm{L}}$ intake or FCM produced. Fortunately, they also aggregated and presented results for cows that completed lactations (about a third of all enrolled cows) within the assigned feeding systems. This would be a more realistic long-term view of performance under grouping strategies (i.e., herd at steady state). In this analysis, cows receiving 2 TMR produced $198 \mathrm{~kg}$ more milk, $177 \mathrm{~kg}$ more FCM, and weighted $36 \mathrm{~kg}$ less than cows receiving 1 TMR at the end of one lactation (Cassel et al., 1984). As done in previous studies, Cassel et al. (1984) used DIM plus a milk threshold as the grouping criteria; also, diets were not formulated according to group requirements.

McGilliard et al. (1983) demonstrated an advantage with respect to the homogeneity of grouped cows when using multiple TMR nutritional groups. That research did not include economics, which would have favored multiple-TMR grouping. An important contribution of McGilliard et al. (1983) was the introduction of a new criterion for grouping lactating cows based on actual nutritional requirements. This criterion consisted in a cluster system, which demonstrated superiority over other grouping criteria, such as milk yield, FCM, or FCM and BW combined for attaining more homogeneous groups. McGilliard et al. (1983) prompted other researchers to revisit the concept of nutritional grouping under a new, more efficient, strategy of selecting cows for nutritional grouping purposes. Later, the same group of researchers (Schucker et al., 1988) was partially able to replicate their theoretical simulation predictions in commercial dairy farm conditions. Schucker et al. (1988) reported only numerical advantages for grouping cows by cluster (by TDN and CP) compared with grouping cows by milk production level for either feed cost savings or additional production. Another followup simulation study from the same group (Pecsok et al., 1992) reported a marginal increase in productivity, in addition to less nutrient usage, when increasing the number of TMR clusters; this signaled a clear economic advantage.

Using simulation modeling, Williams and Oltenacu (1992) studied 7 grouping criteria under 3 potential milk production levels that were subject to 2 or 3 TMR. Their grouping criteria included (1) a requirement of energy and protein, cluster per kilogram of DMI (McGilliard et al., 1983), (2) cluster per kilogram of NDF, (3) DIM, (4) milk, (5) FCM, (6) dairy merit [FCM/ metabolic BW $\left.\left(\mathrm{BW}^{0.75}\right)\right]$, and $(7)$ dairy merit weighted by DIM. They confirmed the results of McGilliard et al. (1983), indicating that the cluster method was the most efficient grouping criterion and that the grouping based solely on milk production was the least efficient method. They reported that $3 \mathrm{TMR}$ had greater IOFC than 2 TMR regardless of the grouping criteria or the potential level of milk production. When using the best grouping criterion of cluster (either per kilogram of DMI or per kilogram of NDF), the IOFC gain was $\$ 21, \$ 33$, and $\$ 40$ with 3 TMR compared with 2 TMR for potential milk production levels of 8,000, 9,000 and $10,000 \mathrm{~kg} / \mathrm{cow}$ per $305 \mathrm{~d}$ of lactation, respectively.

Østergaard et al. (1996) used a comprehensive stochastic dynamic herd simulation model, SIMHERD (Sorensen et al., 1992), to evaluate the effects of mul- 
tiple TMR on milk production and economics. They calculated a net revenue that included the sales of milk and livestock (discounted from feed costs), insemination, capital investment costs, and other miscellaneous costs. Economic results were not directly presented as differences between the number of TMR groups, but as aggregates confounded with other factors, such as culling rate, reproductive efficiency, milk productivity, and their interactions. Nonetheless, Østergaard et al. (1996) reported that the 1 TMR strategy was economically inferior to 2 or 3 TMR due to lower milk production and higher concentrate intakes. These gains occurred even though they used a minimum milk production threshold according to DIM to enroll cows for regrouping. These criteria for grouping can be considered the least effective of all (McGilliard et al., 1983; Williams and Oltenacu, 1992). An important contribution of Østergaard et al. (1996) was the inclusion of the interaction of other herd management practices, such as reproduction or culling on the herd dynamics, with the grouping strategies. Their conclusion was that multiple TMR groups were economically superior, but this conclusion was heavily confounded by other herd management strategies, which would likely affect the composition of the herd and groups.

St-Pierre and Thraen (1999) used a stochastic simulation model to study milk production changes to nutrient supply (energy and protein) according to nutritional grouping strategies. They confirmed that the cluster criterion to group cows was optimal (McGilliard et al., 1983) and used it for further analyses. They reported an IOFC gain of $\$ 44 /$ cow per year when switching from 1 to 2 TMR, and \$33/cow per year when switching from a 2 to 3 TMR grouping strategy. On a herd basis, these differences were explained as an aggregate of both an increase in milk production and a decrease in $\mathrm{NE}_{\mathrm{L}}$ and $\mathrm{CP}$ consumption as the nutritional feeding groups increased. It was assumed that no milk losses occurred because of grouping changes and that fresh cows and primiparous cows were treated equally as all other lactating cows in the herd.

Earleywine (2001) reported between $\$ 10$ and $\$ 44 /$ cow per year greater IOFC for multiple lactation TMR groups. Analyses in Earleywine (2001) consisted of assigning 1 of 5 possible forage-to-grain ratio diets reported in Tessmann et al. (1991b). Earleywine (2001) tested other management strategies, such as concentrated calving and frequency of diet reassignment together with nutritional grouping. In that study it was concluded that multiple TMR lactation-stage nutritional groups had the greatest economic benefit compared with a single TMR group strategy. Under continuous calving, 2 TMR had $\$ 38$ and 3 TMR had
$\$ 44$ more IOFC than 1 TMR. Earleywine (2001) did not distinguish early postpartum cows or consider deleterious effects of moving cows between groups.

More recently, the concept of nutritional grouping and multiple TMR was revisited in simulation research using data from Wisconsin dairy farms. Cabrera et al. (2012) followed McGilliard et al. (1983) in developing a decision support tool (http://dairymgt.info/tools.php; Grouping Strategies for Feeding Lactating Dairy Cattle) as a static deterministic simulation model that calculates IOFC and net returns according to herd-specific characteristics and nutritional grouping strategies. This tool can include user-defined potential milk production losses and additional management, labor, or equipment costs related to nutritional grouping. This model does not distinguish early postpartum cows, assuming that cows are at their milk production potential (change in diets are assumed to be optimal so that milk production does not change with groups and economic gains derive from nutrient cost savings). Even though the decisionsupport tool captures the essence of nutritional grouping, the analysis is highly dependent on user-input parameters. Using anonymous data from 30 Wisconsin dairy herds with this new tool, Cabrera et al. (2012) reported an average IOFC gain for 3 TMR compared with 1 TMR of $\$ 396 /$ cow per year ( range $=\$ 161-580$ ). These gains were made under the assumption that no milk losses would occur because of regrouping. These reported values are much higher than previous or later reports and could have been overestimated. Two important reasons for these possible overestimations: (1) very high group nutrient requirements, 83rd percentile, were used to determine group diet specifications, and (2) high predefined $\mathrm{NE}_{\mathrm{L}}$ and $\mathrm{CP}$ concentrations were used for the 1 TMR diet (presumed to be the same as the highest group of the 3 TMR groups). Also, the calculated nutrients requirements in the tool ignored growth requirements of first and second lactation cows as well as herd structure dynamics.

In a refined model from Cabrera et al. (2012), Cabrera and Kalantari (2014) included population dynamics and stochasticity into the calculations used to study data records from 5 Wisconsin dairy farms with sizes ranging from 331 to 1,460 cows. They reported that economic efficiency, measured as IOFC, consistently increased as groups increased from 1 to 2 and from 2 to 3 TMR in all the farms. The magnitude of improvement was, on average, $\$ 21$ from 1 to 2 TMR and $\$ 25$ from 2 to 3 TMR. The research made evident that an interaction occurred between grouping and herd size, and larger herds could take advantage of a greater number of nutritional groups. The analysis included milk production losses in the amount of $1.82 \mathrm{~kg} / \mathrm{d}$ for $5 \mathrm{~d}(9.1 \mathrm{~kg}$ total $)$ 
every time a cow was moved from a 1 TMR nutritional group to another because of changes in diet or social effects; the reported IOFC gains would increase by 48 or $30 \%$, respectively, if no milk losses had been assumed. One important aspect of this analysis was the inclusion of monthly regrouping episodes throughout a full year.

An ongoing study by the same group in Wisconsin (Kalantari et al., 2015) reported an IOFC gain of $\$ 39$ for 2 over 1 TMR, and $\$ 8$ for 3 over 2 TMR. They also reported that in large herds there would still be a gain with 4 compared with 3 TMR, but it would be very small (\$3). As in Cabrera and Kalantari (2014), Kalantari et al. (2015) separated fresh cows (calving to $21 \mathrm{~d}$ postpartum) as a unique and obligated group receiving its own diet, a situation that is common practice in the dairy industry today (Contreras-Govea et al., 2015). Had the early postpartum group been removed, the IOFC difference between grouping and no grouping would have increased. The same milk losses were assumed by Cabrera and Kalantari (2014) when each cow was regrouped $(9.1 \mathrm{~kg} /$ cow per move). The IOFC would have increased by $\$ 18$ and by $\$ 2 /$ cow per year for 2 versus 1 and 3 versus 2 TMR, respectively, without such an assumption. Also, they analyzed the situation in which first-lactation cows would have already been separated and fed their own TMR, another common practice in commercial dairy farms (Contreras-Govea et al., 2015). In such a situation, the IOFC gain of grouping (only the rest of the cows) would be lowered by $\$ 6 /$ cow per year for 2 versus 1 TMR and by $\$ 1.5 /$ cow per year for 3 versus 2 TMR. All these IOFC gains were explained by higher milk production and lower feed costs thanks to more nutritional groups. Kalantari et al. (2015) used a nutrient requirement-based system to estimate the energy and protein requirements of a cow with a given milk production. Moreover, they followed the daily nutrients intake of each cow, including energy, to determine BW and BCS changes throughout the lactation dynamically. Under such conditions, arbitrary BCS bounds were used to control the BCS range of cows. Those cows with very low BCS $(\leq 2.0)$ and large negative energy balance were destined to decrease milk production rather than continuing to lose BCS: the model predicted that 2 or 3 TMR grouping strategies will have much less proportion of under-conditioned cows compared with 1 TMR, and therefore higher milk production. Conversely, cows with very high BCS $(\geq 4.5)$ were destined to decrease their DMI rather than keep increasing their BCS: the model predicted that multiple TMR grouping strategies would have a lower proportion of over-conditioned cows compared with 1 TMR. Lower feed costs with more TMR groups were primarily explained due to less RUP costs (less RUP consumed). The overall RUP cost savings largely offset higher costs of energy and RDP in multiple TMR strategies. Kalantari et al. (2015) found many important advanced characteristics; among them, a full individual cow daily nutrient balance including $\mathrm{NE}_{\mathrm{L}}$, $\mathrm{MP}$ (RUP and RDP), a daily BW (including growth), and BCS change, which all follow cow status (i.e., lactation, DIM, pregnancy).

The only simulation study that made a complete economic analysis beyond IOFC (Østergaard et al., 1996) concluded that multiple TMR feeding was economically superior, although it included several other confounding factors that masked the effect of the grouping. Therefore, its results are difficult to interpret, replicate, or systematize.

Simulation studies have not included the effect of potential milk losses (or included only at an arbitrary level) even though these studies used optimal grouping techniques and more precise diet specifications, which is an important difference from earlier field studies. In this context, it is understandable that the industry has not widely adopted nutritional grouping strategies beyond separating early postpartum, dry cows, and, occasionally, first-lactation cows. It is also intuitive to assume that the advent of the recombinant (r)BST as a widely used technology that improves production efficiency (feed to milk conversion and greater milk production persistence) has played a role in promoting 1 TMR diet for all lactating cows (Allen 2008; 2009).

Studies combining field trials and simulation techniques are still needed to assess the full economic benefit of nutritional grouping strategies in modern dairy farming. These should include the state-of-theart grouping techniques applied to actual conditions of commercial dairy farms, coupled with long-term projections, and under the impact of other common management strategies, such as replacement policies, reproduction programs, use of $\mathrm{rBST}$, and milk quality protocols, which would interact with nutritional grouping strategies. Moreover, future studies should include $\mathrm{BW}$ and $\mathrm{BCS}$ changes of cows according to grouping strategies and their potential effects on herd health and farm economics. Future studies should also examine the frequency and timing of regrouping. Finally, upcoming studies should consider the potential environmental benefits of grouping strategies, which should also be related to farm economics.

In short, the most important factors determining the economic efficiency and value of nutritional grouping are: (1) criteria for grouping; (2) diet nutrient specifications; (3) effects on milk production; (4) health and environmental benefits; (5) number, size, and frequency of grouping; and (6) additional costs and benefits. In 
the following sections, we discuss all these factors except the last one. Additional costs and benefits refers to management, labor, machinery, equipment, and feed additives that would increase or decrease in their usage according to group strategies, but more importantly, within specific farm conditions. These need to be evaluated on a specific farm-by-farm basis; because of this, published studies for this topic are nonexistent.

\section{Criteria for Grouping}

The criteria used to split cows into more homogeneous feeding groups is a critical factor that determines the effectiveness of nutritional grouping strategies (Smith, 1976). Originally McGilliard et al. (1983), then Williams and Oltenacu (1992) and St-Pierre and Thraen (1999), defined and compared the effects of different grouping criteria of nutritional grouping in lactating cows. McGilliard et al. (1983) studied the following criteria: (1) test milk yield, (2) 4\% FCM (0.4 milk +15 fat yield $),(3)$ dairy merit $(100 \times 4 \% \mathrm{FCM} /$ $\mathrm{BW}^{0.75}$ ), and (4) cluster. Each additional factor in the grouping criteria was expected to reduce the variation of nutritional requirements and to foster more homogeneous nutritional groups. The cluster method was an important conceptual contribution of McGilliard et al. (1983) that consists of grouping lactating cows according to their simultaneous requirements of protein and energy per kilogram of DMI. In this method, individual cow requirements for energy and protein are first calculated according to their maintenance (a function of BW), growth, and production (a function of milk yield) requirements. McGilliard et al. (1983) described the statistical method of grouping animals according to the number of groups and group sizes by using their nutrient requirement spatial distribution and distance (energy and protein requirements of cows). Although they and other researchers (Williams and Oltenacu, 1992; St-Pierre and Thraen, 1999) used protein and energy (with same weight) as the nutrient drivers for the cluster, McGilliard et al. (1983) demonstrated that different weight of nutrients or additional nutrients could also be used in the cluster grouping. Their results clearly indicated that grouping effectiveness, defined as the comparison of variances between groups with respect to variances within groups, increased almost linearly as the grouping criterion included more information about the cows. Consequently, effectiveness (from lowest to highest) depended on milk yield, FCM, dairy merit, and cluster. Cluster was substantially superior to dairy merit at making cows more alike in a group. Indeed, ranking cows solely based on energy or protein requirements was much more effective than any other of the methods besides cluster. Ranking cows based on energy requirements was better than ranking them by protein requirements. Schucker et al. (1988) used the cluster (by TDN and CP) approach in 10 commercial dairy farms and compared it to grouping cows by milk production. They reported clustered groups to be clearly more homogeneous in nutrient requirements.

Williams and Oltenacu (1992) compared 7 criteria for grouping nutritional cows in a simulation study. In addition to the ones studied by McGilliard et al. (1983), they included (1) DIM, (2) dairy merit weighted by DIM $\left[\left(100 \times 4 \% \mathrm{FCM} / \mathrm{BW}^{0.75}\right) \mathrm{e}^{-(\mathrm{DIM} / 100)}\right]$, and (3) modified cluster per kilogram of NDF (instead of per kilogram of DMI). The reason why they proposed cluster per kilogram of NDF was to avoid the interaction between diet, fill capacity, and DMI (NDF ingestion capacity limits DMI for a particular diet). They hypothesized cluster per kilogram of NDF would have better outcomes than the cluster per kilogram of DMI. Williams and Oltenacu (1992) also included an economic module to evaluate the IOFC according to grouping criteria. They consistently found that both cluster $\left(\mathrm{NE}_{\mathrm{L}}\right.$ and $\mathrm{CP}$ per $\mathrm{DMI})$ and modified cluster $\left(\mathrm{NE}_{\mathrm{L}}\right.$ and $\mathrm{CP}$ per NDF) methods were the most effective (the cluster per NDF surpassed the other by a small difference). They reported IOFC (milk sales - feed costs) to be $\$ 21$ $(\$ 42-21), \$ 33(\$ 73-40)$, and $\$ 40(\$ 61-21)$ greater with 3 TMR groups than with 2 TMR groups for levels of production $8,000,9,000$, and $10,000 \mathrm{~kg} /$ cow per year, respectively. These increases responded to increased milk sales because feed costs were higher with 3 TMR groups. Williams and Oltenacu (1992) differentiated potential from actual production so that the value of grouping was in the extra milk produced (closer to potential) by cows receiving diets closer to their requirements. However, the diets provided to the samesize groups were predefined and fixed regardless of the grouping criterion. Williams and Oltenacu (1992) did not distinguish early postpartum or first-lactation cows, neither did they evaluate the IOFC gain from 2 versus 1 TMR groups. The magnitudes of the IOFC variations according to group and number of group criteria are depicted in Figure 1.

Based on Figure 1, it can be concluded that using the optimal group criterion could have a similarly high or even higher economic effect than increasing the number of groups from 2 to 3 TMR. For example, going from 2 to 3 TMR groups with test-day milk - the poorest criterion - had an estimated IOFC gain of $\$ 17$, which was $\$ 44$ less than simply staying at 2 TMR NDF-clustered groups.

Later St-Pierre and Thraen (1999) compared, with a Monte Carlo simulation model, 4 strategies to group 


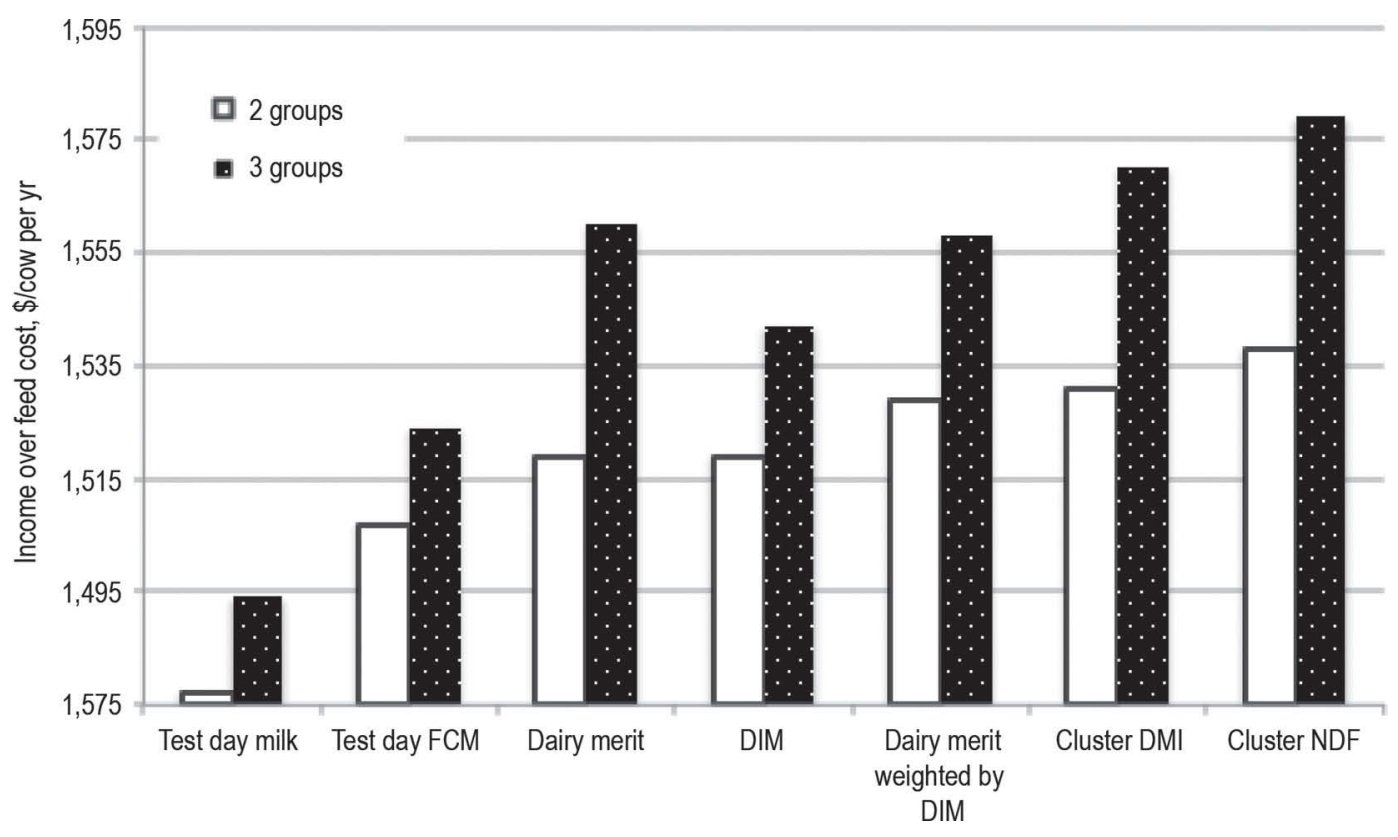

Figure 1. The economic value of the optimal grouping criteria for a herd producing $10,000 \mathrm{~kg} / \mathrm{cow}$ per year. Adapted from Williams and Oltenacu (1992). Dairy merit is $100 \times 4 \% \mathrm{FCM} /$ metabolic BW.

milking cows: (1) actual FCM, (2) estimated $\mathrm{NE}_{\mathrm{L}}$ concentration requirements, (3) estimated $\mathrm{CP}$ concentration requirements, and (4) cluster (McGilliard et al., 1983). St-Pierre and Thraen (1999) consistently found that cluster outperformed the other 3 methods, a circumstance which revealed an increased IOFC of $\$ 44$ and $\$ 77$ when 2 and 3 TMR clusters groups were used compared with 1 TMR group, respectively.

After McGilliard et al. (1983) and later validation studies (Schucker et al., 1988; Williams and Oltenacu, 1992; St-Pierre and Thraen, 1999), it is clear that the cluster is the most efficient method to group cows, a method resulting in more homogeneous groups with the least difference among cows inside the group and with the most difference among groups (therefore being the method with higher economic potential). Even when the cluster method has been widely accepted and adopted in the research literature (St-Pierre and Thraen, 1999; Kalantari et al., 2015), it has not resonated for practical application in the industry for effective dairy farm management (Jonker et al., 2002; VandeHaar, 2011; Contreras-Govea et al., 2015). For example, farmers who reported performing some level of nutritional grouping have indicated using other methods for grouping their cows (Contreras-Govea et al., 2015). This could happen because of several independent or combined reasons, such as (1) not knowing the benefits of cluster in comparison to milk, FCM, or DIM grouping criteria; (2) conflicts of grouping with other management practices, such as reproduction or health; (3) grouping calculations, such as determination of individual cow's $\mathrm{NE}_{\mathrm{L}}$ and $\mathrm{CP}$ requirements not readily, easily, or permanently available, and therefore impractical; and (4) grouping modifications and adjustments farmers normally force cows into different groups depending on their health status.

It is obvious that a simple switch to cluster, for those herds performing grouping with a different criterion, will make a substantial effect in the herd economic efficiency. Nonetheless, an important educational effort is required. The effort should engage DHIA processing centers and dairy management software companies so that farmers have a practical and permanent way to manage groups at the farm level according to specific farm conditions. For those managers using only 1 TMR and interested in considering nutritional grouping, cluster grouping should be the preferred criterion. Under special circumstances, in which a compromise in the grouping criterion is needed because of other herd management strategies, priorities should be given to the next most efficient grouping method following results from McGilliard et al. (1983) and Williams and Oltenacu (1992): (1) dairy merit, (2) dairy merit weighted by DIM, (3) DIM, (4) FCM, and (5) milk yield. Decision-support tools, similar to the one available at the Wisconsin Dairy Management Website (http://dairymgt.info/tools.php; Grouping Strategies for Feeding Lactating Dairy Cattle), that demonstrate 
the value of grouping according to grouping criteria can be effective to educate, encourage, and promote efficient grouping strategies in dairy farms.

\section{Diet Nutrient Specifications}

A diet for a group of cows is normally formulated for a greater-than-group-average milk production cow (Weiss, 2014). Weiss (2014) argues that formulating for the average cow milk production in a group will approximately underfeed half of the cows (in which milk production will decrease) and overfeed the other half (in which milk production would not change); therefore, diets should be over-formulated. The level of over-formulation would depend on [more $(+)$ or less $(-)$ over-formulation] milk price $(+)$, feed costs $(-)$, variability of ingredients composition $(+)$, less homogeneous pens $(+)$, good feeding management $(-)$, and good facilities (-). Regarding the homogeneity of pens, Weiss (2014) contends that diverse cow populations in a group must be fed diets that substantially exceed the nutrient requirements of the average cow. The goal here is to ensure that high-producing cows maintain their productivity. Although nutrient concentration in the diet of a cow depends on BW, parity, DIM, and milk production and composition, milk production and DIM are the most important factors and vary enough to warrant substantial variation in nutrient needs among cows (Weiss, 2014). Furthermore, at similar milk yields, cows in the first month of lactation can consume 4.5 to $6.8 \mathrm{~kg}$ less feed than cows later in lactation. Consequently, they require much higher nutrient-dense diets. When grouped with later lactation cows, cows in the first month of lactation need highly over-formulated diets. Grouping strategy and subsequent group feeding behavior influence DMI and could have a tremendous effect on milk productivity, health, and profitability, as feed intake is the most important factor of milk yield and body condition change during lactation (Grant and Albright, 2001). More homogeneous groups of cows according to cow nutrient requirements would aide proper diet formulation and reduce nutrient excretion (St-Pierre and Thraen, 1999). Formulation according to milk production depends on the group variability; usually a diet formulation can support 10 to $20 \%$ more milk because of the higher intakes of higher-producing cows (Weiss, 2014) and, therefore, cows with 1.2 times more nutrient requirement than the offered diet will not receive enough nutrients.

VandeHaar (2011) adds that when a single TMR diet is fed to all lactating cows it will usually be formulated for the high-producing cows; as a result, it will be more nutrient-dense than optimal for later-lactation cows. This will waste a large proportion of these nutrients.
Indeed, he continues, it is not possible to formulate a single TMR for maximum production because a diet that is optimal for one stage of lactation is not optimal for another stage of lactation. For example, a low-fiber, high-digestible carbohydrate diet that could be optimal for production, reproduction, and health in peak lactation would be inadequate for early postpartum or late-lactation cows. Likewise, early postpartum cows would increase the incidence of displaced abomasum and acidosis and late-lactation cows would become over-conditioned with such a diet (VandeHaar, 2011). Fat cows are more susceptible to health issues in their next lactation, which will result in an increased body fat mobilization, impaired fertility, extended lactation, and overall decreased milk yield (Cameron et al., 1998).

Milk Lead Factors. Milk lead factors are multiplicative coefficients to the average milk production of a group of cows for diet formulation purposes (Jones et al., 1978). Stallings and McGilliard (1984) proposed use of average milk +1 SD (average milk $\times 1.3$ ) or approximately the 83rd percentile method (assuming a normal distribution) to formulate the optimal diet for a group. St-Pierre and Thraen (1999) revisited this issue with an economic optimization model; they found lead factors of similar magnitude to the ones reported previously (Stallings and McGilliard, 1984) and agreed with the need to have different lead factors for different groups. Thus, St-Pierre and Thraen (1999) proposed to use separate $\mathrm{NE}_{\mathrm{L}}$ and $\mathrm{CP}$ lead factors and concluded that the determination of lead factors warrants additional research because of its significant effect on resource allocation and profitability. Weiss (2014) proposed to formulate the group diet safely for average milk yield production +1.3 SD units, but using the group average for either milk yield or DMI instead of for the milk production goal.

Milk lead factors are practical and popular in the dairy industry. Nonetheless, it is clear they interact largely with grouping homogeneity. Also, lead factors do not consider nutrients for maintenance or growth and they might not be the optimal way to define group diet formulations. Farmers' great effort into grouping the most homogeneous cows could be defeated by using lead factors in diet formulation, because the resulting diets would not necessarily correspond to the group requirements. If cows are efficiently grouped through a cluster method, the individual, and therefore group, distribution of nutrient requirements would become known, and the ensuing diet would be based on their full nutrient requirements rather than solely on milk production.

Optimal Nutrient Allocation. It is intuitive to think that the best way to feed cows is by allocating nutrients closer to their requirements, as postulated with 
precision feeding. Under the assumption that today it is not difficult or impractical to estimate precisely the level of nutrient requirements and DMI (or NDF) on an individual cow basis, it would be ideal, then, to provide a diet that covers and adjusts to those needs and changes. In an ideal situation in which each cow is fed individually, each cow would receive the exact amount of $\mathrm{NE}_{\mathrm{L}}, \mathrm{CP}$, and other nutrients required for maintenance, growth, and production (i.e., perfect precision feeding). This is not practical in many dairy farm production systems where groups of cows need to be fed with the same nutrient concentration in their diet. A compromise is needed: the diet should be formulated in a way that is closer to the overall group requirements. Obviously this depends on the homogeneity of the group (grouping criterion), which determines how alike cows are in their nutrient concentration requirements within a group. Providing that cows are optimally grouped (i.e., following cluster), the diet should approximate the actual group requirements and its variability. Differences between diet and requirements would be alleviated by cow DMI adjustments (Weiss, 2014). Under these premises, milk lead factors are not needed. Some studies recognized this fact and, accordingly, did not use a milk lead factor to evaluate group-feeding strategies (Williams and Oltenacu, 1992; Cabrera et al., 2012; Kalantari et al., 2015); they based their diet formulations strictly on the group's required nutrients (with or without a factor). Even though Williams and Oltenacu (1992) did not use milk lead factors, they used fixed diets to which cows had to adapt once they were regrouped, rather than adapting the diets to group needs.

Kalantari et al. (2015) used the average and a factor of $\mathrm{SD}$ to determine the $\mathrm{NE}_{\mathrm{L}}$ and $\mathrm{MP}$ concentrations (each one independently) of a group diet according to the distribution of group requirements. Also, importantly, Kalantari et al. (2015) took into consideration, dynamically, the projected group performance under a proposed diet. The decision on the diet concentration was economically based (maximum IOFC), but it did not ignore BW and BCS changes according to diet formulation. Formulating diets with a concentration above $\mathrm{NE}_{\mathrm{L}}$ average resulted in an undesirable proportion of obese cows. Therefore, it was concluded that feeding the average $\mathrm{NE}_{\mathrm{L}}$ concentration of the requirements of a group would be a better level. For MP, they tested MP, $\mathrm{MP}+0.5 \mathrm{SD}$, and $\mathrm{MP}+1 \mathrm{SD}$, and selected the latter, which was also chosen as the preferred concentration at which nutritionists would formulate diets (Kalantari et al., 2015). A visible difference in the nutrient offered throughout lactation using nutrient requirements (Kalantari et al., 2015) or using milk lead factors (e.g.,
Stallings and McGilliard, 1984) is depicted in Figure 2, upper panel.

The $\mathrm{NE}_{\mathrm{L}}(\mathrm{Mcal} / \mathrm{kg}$ of $\mathrm{DM})$ and MP (g/100 g of DM) concentrations offered in the diet with lead factors are always greater (or, at best, equal) to the amounts offered according to the nutrient requirements of average $\mathrm{NE}_{\mathrm{L}}$ and average $+1 \mathrm{SD} \mathrm{MP}$ (Figure 2, upper panel). Under the reasonable assumption that cows are optimally grouped, production would not change whether they are fed based on group milk lead factors or on nutrient requirements. However, it is clear that using group $\mathrm{NE}_{\mathrm{L}}$ requirements results in a more desirable normal-like distribution of herd BCS, which is completely different than the distribution when using lead factors (Figure 2, bottom panel). The projected distribution with lead factors ends up with a large proportion of over-conditioned animals with BCS $\geq 4$.0. It should be noted that none of these methods produced optimal diet specifications in terms of $\mathrm{NE}_{\mathrm{L}}$ or MP concentrations. Future research should pursue group diet optimization to attain better economic and physiological results according to requirements.

These findings support Allen (2000, 2008, 2009), who suggested that feeding more than one diet to lactating cows manages body condition without compromising milk yield, whereas feeding one diet to all lactating cows always presents a compromise between achieving higher milk yield or managing body condition. Allen (2008; 2009) argued that feeding only one diet formulated to limit over-conditioned, late-lactation cows limits the milk yield of peak-producing cows; those studies also contend that feeding only one diet formulated for peakproducing cows results in over-conditioned cows. Overconditioned cows are at high risk for culling during the next lactation because of metabolic disorders, poor health, and reproductive failure (Allen, 2008, 2009).

The nutrient requirements of lactating cows are not only determined by milk yield and growth, but also by energy partitioning as lactation progresses (Allen, 2009). Thus, different diets are warranted for early and late lactation. Little energy is partitioned to body condition in peak-producing cows because both insulin concentration in the blood and insulin sensitivity of tissues are low (Allen, 2009). Peak lactation cows require a greater glucose production in the liver to be able to produce lactose in the mammary glands, which promotes milk production. The liver glucose production depends on the starch content of the diet, and this is why peakproducing cows flourish on highly fermentable diets (Allen 2008, 2009). Feed intake in peak-producing cows is limited by gut fill. However, highly fermentable diets can depress feed intake, cause excessive weight gain, and condition gain in late-lactation cows (Allen, 2009). 

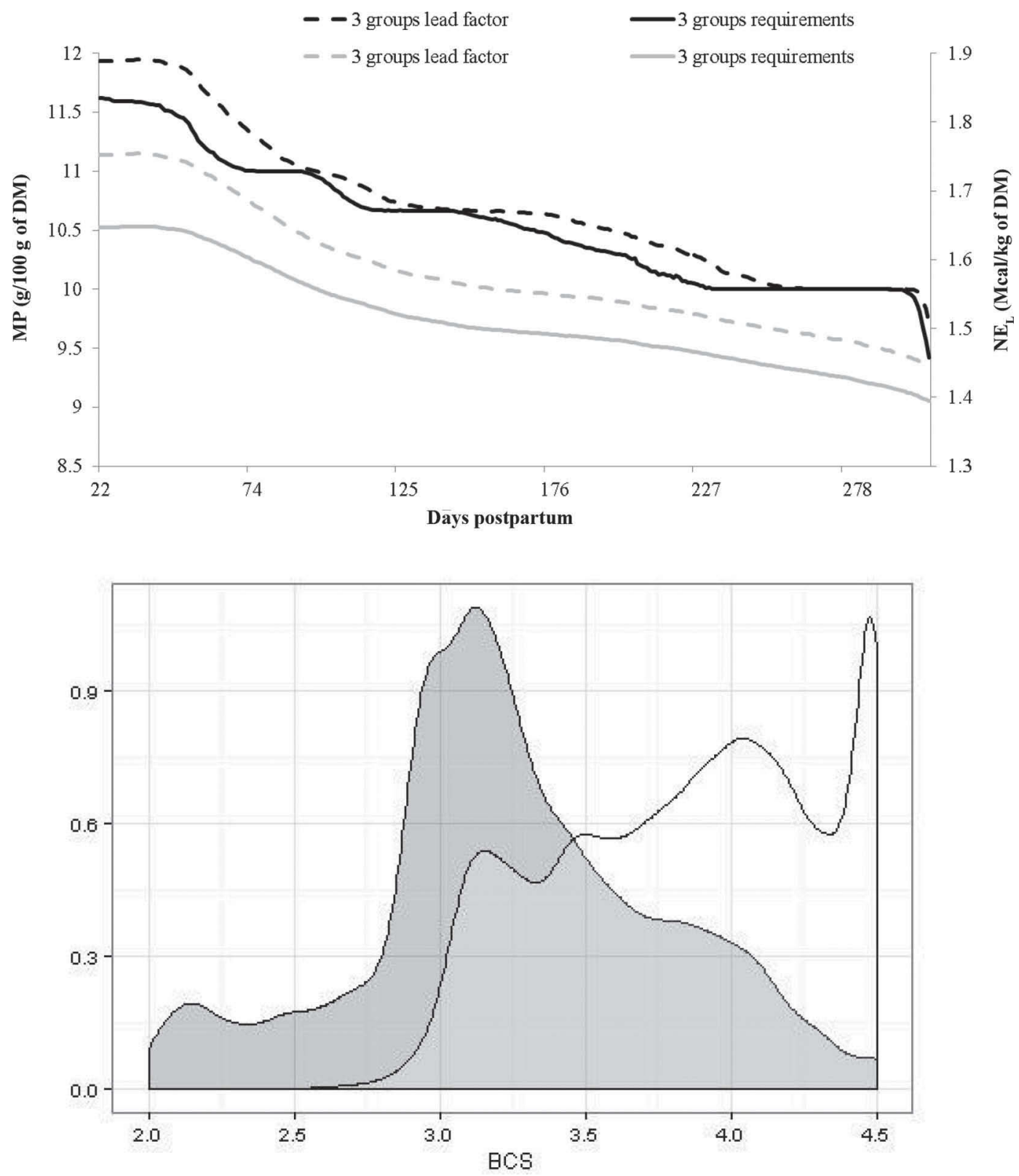

Figure 2. Offered diets and BCS distributions projected with the Kalantari et al. (2015) model for a 727-cow Wisconsin herd with 3 TMR feeding groups. Upper panel: average offered diet $\mathrm{NE}_{\mathrm{L}}$ (light shade) and $\mathrm{MP}$ (dark shade) at average $\mathrm{NE}_{\mathrm{L}}$ and average $+1 \mathrm{SD} \mathrm{MP}$ diet formulation according to Kalantari et al. (2015; 3 group requirements) and diets that would have been formulated based on milk lead factors (high group $=1.14$, middle group $=1.10$, and low group $=1.21$ ) according to Stallings and McGilliard (1984; 3 group lead factor). Bottom panel: resulting BCS distributions with 3 group requirements (dark shade) and with 3 group lead factor (light shade).

As lactation progresses, production declines and cows can be fed higher-forage diets without compromising milk yield because gut fill is less limiting (Allen, 2009). Glucose demand also declines because less is needed to produce milk lactose, and blood glucose concentration increases, stimulating greater secretion of insulin. Insulin causes body tissues to produce fat, partitioning energy to body condition (Allen, 2009). As lactation progresses, insulin concentration and insulin sensitivity increase and more energy is partitioned to body tissue at the expense of milk yield. Therefore, milk production declines and highly fermentable diets increase glucose and insulin to a greater extent, so that highly fermentable diets depress milk yield and aggravate the fattening of late-lactation cows (Allen, 2008, 2009).

With the information available, our conclusion is that group diet specifications should be (1) based on group complete nutrient requirements and not solely on 
milk production (whether using a lead factor or not), (2) formulated at different levels for different nutrients, and (3) future research should look for ways to optimize group-diet formulations.

\section{Effects on Milk Production}

Several studies have shown no milk production advantage for more than one diet (Coppock et al., 1981) and some even reported a significant drop in milk production when grouping (Smith and Coppock, 1974); but recent studies seem to show the reverse (St-Pierre and Thraen, 1999; Kalantari et al., 2015). Coppock (1977) argued that the milk production decrease was due to 2 important potential issues when grouping: (1) social and (2) dietary. Coppock (1977) indicated that moving cows between groups (at the time, in all cases, small groups of 20 cows or less) caused a predictable social disturbance that resulted in milk production loss. However, it was concluded that, under certain commercial dairy conditions, cows can be regrouped without the social disturbances that would seriously decrease milk production (Coppock, 1977). Regarding the dietary change effects, these were believed to be of greater importance, as data demonstrated drastic drops of DMI and milk production were directly related to diet changes. It is important to note that diet changes were drastic and that production levels were much lower than today's standards. Nonetheless, there was evidence that cows could maintain DMI and productivity after diet changes when feeding for ad libitum intake (Coppock, 1977), a common practice in the contemporary dairy industry. As already seen, previous research centered on cows grouped in small groups, having low productivity, and often confounded with drastic diet density changes simultaneously. VandeHaar (2011) contends that the effect of group change is multifactorial and confounded together with DIM, pregnancy status, rBST timing and use, stocking density, heat stress, and social interactions.

Social Effects. Some studies maintained constant diets while also isolating the social effect of grouping. Brakel and Leis (1976) reported a $0.51 \mathrm{~kg}$ or $3 \%$ decrease in $4 \% \mathrm{FCM}$ of groups of 4 cows moved to groups of 20 cows, but only during d 1 of the move. Hasegawa et al. (1997) reported a $4.7 \%$ milk yield decrease during the second week after moving half of the cows between 2 pens of primiparous cows. Other researchers did not find changes in milk yields (Clark et al., 1977). von Keyserlingk et al. (2008) placed a new cow into a small established group of 11 cows, reporting a decrease in milk yield on the moved cow of $3.7 \mathrm{~kg}$, but only during d 1 of the move. Those authors speculated that one of the reasons for the limited effect of the grouping was the relatively minor social disruption, given the small size and stability of the original group. von Keyserlingk et al. (2008) hypothesized that the effect would be greater with larger groups, as it is often the case in modern dairy farms. This argument contradicts Estevez et al. (2007), who maintained that the disruptive effects of regrouping large groups would be reduced because stable social relationships are difficult to maintain in very large groups. Albright (1978) speculated that cows can only recognize 100 other animals. Therefore, cows in large groups would rather accommodate to the space and resources available than try to establish a hierarchy that they would not be able to keep.

Overstocking is prevalent in the US dairy industry (Bewley et al., 2001). Stall overstocking and, more importantly, feeding bunk overstocking exacerbates competition among cows, decreases DMI, decreases milk yield (Nordlund and Cook, 2006), and could interact negatively with nutritional grouping strategies depending on the resulting stocking density and grouping criterion applied. If the number of cows per group is adjusted to the available facilities, cows will end up with the same stocking density after being regrouped (Cabrera et al., 2012). However, detrimental effects of overstocking can aggravate if the grouping criteria does not incorporate age, parity, BW, BCS, or other factors related to dominant and subordinate cows, which could ameliorate feeding competitive problems in overstocking conditions (DeVries et al., 2004; Huzzey et al., 2006).

Social rank is related to age and BW; thus, primiparous cows often occupy lower positions than multiparous cows in a group's dominance hierarchy (Botheras, 2010). This suggests primiparous cows should be managed in a separate group. It has been documented that primiparous cows feeding behavior and performance improve when they do not have to compete with multiparous cows (Krohn and Konggaard, 1979). Krohn and Konggaard (1979) reported that primiparous cows separated from multiparous cows spent 10 to $15 \%$ more time eating, had 0.5 to 2.0 more eating periods per day, and produced 5 to $10 \%$ more milk yield. These results derived from 3 herd experiments with group sizes of 24,70 , and 98 cows, in which the effect of separating primiparous from multiparous cows decreased as the group size increased. The FCM was not different when group sizes were $\geq 70$ cows. This fact indicates that the social effect of hierarchy and dominance between primiparous and multiparous decreases as group size increases.

In a more recent study in 2 commercial dairy herds, Zwald and Shaver (2012) concluded that moving cows 
between pens, without a diet change, did not have deleterious effects on milk yield. They argued that, in today's commercial dairy operations, there may be enough cows in groups or enough resources (such as stalls, bunk space, water, and feed) or both to minimize the negative effects on milk yield observed in other studies. Lower-ranking animals would have the opportunity to eat ad libitum when less competition was present, provided resources and space are available in adequate amounts (Friend et al., 1977; Arave and Albright 1981). Today's commercial dairy herd operations have group sizes and production levels greater than previous studies, which diminishes the effect of social disturbance when cows are moved between pens. With abundant resources and large group sizes (e.g., $>60$ cows), the cost for cows to establish a social hierarchy may be greater than its benefits (Zwald and Shaver, 2012) and, as a consequence, minimal or no milk production decreases may be expected.

Effects of Diet Changes. Provided that cows are optimally clustered and diets are more precisely specified, there is no reason for cows to be deprived of nutrients, considering that homogeneous groups would allow for cows to adjust moderately their DMI to their requirements (Weiss, 2014). This fact is heavily related to optimal nutrient allocation with grouping compared with 1 TMR. Grouped cows (Figure 2, upper panel) seem to receive a diet more in accordance with their requirements.

\section{Health and Environmental Benefits}

Based on previous discussions, it is reasonable to expect improved herd health and reduced nutrient excretion by means of optimal nutritional grouping strategies. Cows fed more precisely through grouping will have less chances of becoming either under- or over-conditioned and, therefore, healthier. Cows optimally grouped will produce more milk, consume less nutrients, and, as a result, excrete less nutrients to the environment. Nonetheless, scientific information for these interactions is limited. For example, evidence exists that low body reserves in late lactation compromises production in the subsequent lactation (Tessmann et al., 1991a) or that lower than $3 \mathrm{BCS}$ (5-point scale) at calving is associated with reduced production and reproduction, whereas higher than 3.5 BCS at calving is associated with reduced DMI, reduced milk yield, and increased metabolic disorders in the next lactation (Roche et al., 2009). That said, multilactation-specific studies on the effect of health effects of nutritional grouping are lacking.

Health Benefits. Kalantari et al. (2015) reported an interesting attempt to capture the effect of nutri- tional grouping on herd BW and BCS. They performed daily cow energy balance calculations as affected by grouping strategies. Cows receiving more energy than needed gained BW and BCS and it was assumed that cows would decrease their DMI if their BCS reached 4.5 (scale 1 through 5), so the maximum allowed BCS was 4.5. Cows receiving less energy than needed lost BCS. Kalantari et al. (2015) assumed cows would decrease milk yield before lowering BCS below 2, so the minimum allowed BCS was 2. Interestingly, they found that overall herd BW distribution of 1 versus 3 nutritional groups did not differ substantially (Figure 3, left panel). This fact is consistent with previous research (Clark et al., 1977; Smith et al., 1978; Cassel et al., 1984; Kroll et al., 1987); however, important differences were noted regarding herd BCS distribution (Figure 3, right panel). The distribution was thick-tailed, with 1 TMR nutritional group having a large proportion of animals either under- (BCS $=2$ ) or over-conditioned $(\mathrm{BCS}=4.5)$. The BCS was normally distributed, with 3 TMR nutritional groups having the largest proportion of animals with optimal BCS between 3 and 3.5. A similar pattern was found in 2 TMR nutritional groups, so they concluded that optimally feeding 2 or 3 TMR nutritional groups promotes a more desirable distribution of herd BCS without changes in herd BW, which would produce healthier herds. Healthier herds will incur in less costs or losses, have improved productivity, and better reproductive performance (Bewley and Schutz, 2008). Therefore, optimal nutritional grouping will promote improved profitability. It is important to remember that Kalantari et al. (2015) forced early postpartum cows (DIM <22 d) to be in a separate group even before testing grouping strategies. The difference in favor of grouping would have been even more dramatic otherwise.

Environmental Benefits. Dedicated simulation studies that have tested the effect of grouping on nutrient use efficiency have consistently found a slight improvement with 2 or 3 TMR nutritional groups. St-Pierre and Thraen (1999) found that N excretion was reduced by $3.7 \%$ and $\mathrm{N}$ efficiency was increased by $5.8 \%$ when feeding 3 TMR cluster groups compared with 1 TMR group. Those authors indicated that additional clusters will not lead to further reductions in $\mathrm{N}$ excretion or increases of $\mathrm{N}$ use efficiency. Also, Cabrera and Kalantari (2014) reported 1.0 and $2.6 \%$ and Kalantari et al. (2015) reported 1.9 and $2.7 \%$ increased N efficiency with 2 and 3 TMR groups compared with 1 TMR group, respectively. Kalantari et al. (2015) found only minimal $\mathrm{N}$ efficiency improvement with $4 \mathrm{TMR}$ nutritional groups compared with 3 TMR groups.

Nonetheless, studies that analyzed data collected from commercial farms showed no improvement in $\mathrm{N}$ 
use efficiency (Jonker et al., 2002; Powell et al., 2006; Arriaga et al., 2009) or P use efficiency (Jonker et al., 2002; Powell et al., 2006) with increased nutritional groups. From those studies, Arriaga et al. (2009) found an increase in $\mathrm{P}$ use efficiency. Jonker et al. (2002) reported that the grouping criteria of studied farms were far from optimal. No farm used the cluster method, most of them used less-than-optimal grouping criteria such as milk production, DIM, or reproductive status, an important factor that likely influenced results against grouping. Based on data from 54 surveyed Wisconsin farms, Powell et al. (2006) stated that feeding lactating cows in groups did not affect milk production, efficiency of $\mathrm{N}$ use, or efficiency of $\mathrm{P}$ use. They did not describe grouping strategies on these farms, but likely these were not optimal, as was later reported on another study of Wisconsin dairy farms (Contreras-Govea et al., 2015). Arriaga et al. (2009) used survey data from 64 dairy farms in the Basque country to analyze $\mathrm{N}$ and $\mathrm{P}$ use efficiency when cows were grouped by DIM. They found no improvement in N use efficiency but a $14 \%$ improvement in P use efficiency. Arriaga et al. (2009) claimed that $\mathrm{P}$ use efficiency increased due to greater milk yield rather than to the feeding of more precise diets. This was different for $\mathrm{N}$ because they recorded greater $\mathrm{N}$ intake with more feeding groups. An important factor that would have influenced those results, as in previous research, was the use of a less-than-optimal grouping criterion, DIM, which was a reflection of the practices

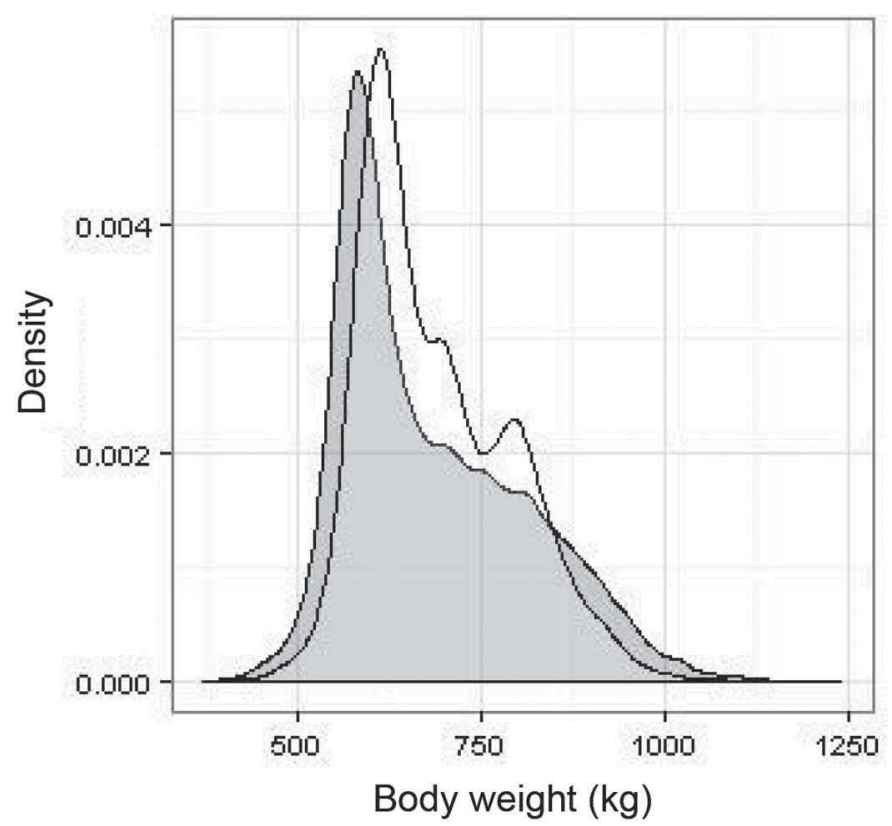

of the studied farms. Regarding greenhouse gas emissions, similar to other nutrients, grouping strategies have the potential to decrease emissions per kilogram of FCM produced (Place and Mitloehner, 2010).

In conclusion, grouping strategies, if optimally performed, will improve nutrient use efficiency and decrease environmental emissions; however, their economic value should be estimated. Decreasing environmental effects should translate to reduced costs or improved benefits. Farmers in the future will need to include these valuations whenever they may be forced to comply with stricter regulations or whenever they can take advantage of incentives to reduce environmental effects.

\section{Number, Size, and Frequency of Grouping}

Number of Feeding Groups. The highest-producing US herds in the 1990s using a TMR feeding system reported to feed an average of 2.9 groups of cows (Jordan and Fourdraine, 1993), which presumably included a group for dry and another for early postpartum cows, so that, on average, only 1 TMR group was used for the rest of the lactating cows. Also, Contreras-Govea et al. (2015) reported that $48 \%$ of Wisconsin and Michigan farms fed only 1 TMR to all lactating cows besides the early postpartum cow group. Based on the literature, Sniffen et al. (1993) found that milk production would increase between 1 and $3 \%$ for 1 versus 2 TMR groups, $2 \%$ for 2 versus 3 TMR groups, and between 0 and 1\%

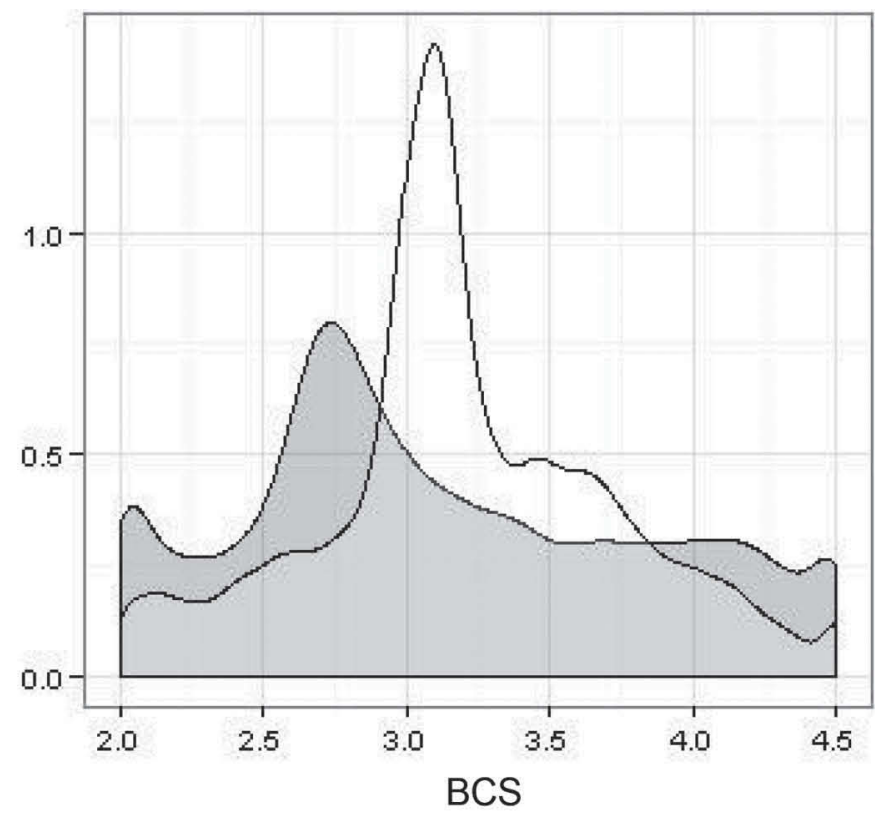

Figure 3. Body weight (left) and BCS (right) density plots from a herd (area under the curves adds to $1=787$ cows) for 1 (dark shade) and 3 (light shade) nutritional groups from Kalantari et al. (2015). 
for 3 versus 4 TMR groups, exposing a clear law of diminishing returns as the number of groups increased and there would be little justification for going beyond 3 TMR lactation groups. Other researchers have also concluded that lactating cows should be divided in 3 TMR feeding groups for optimal efficiency (Grant and Albright, 1997, 2001; St-Pierre and Thraen, 1999). However, the number of groups should be evaluated by farm, as the optimal number of groups would vary depending on herd size and on other factors. Grant and Albright (2001) recommended an early postpartum cow group during the first 3 wk of lactation and 3 TMR groups for the rest of the lactation. St-Pierre and Thraen (1999) reported that IOFC increased by $3.4 \%$ when feeding 3 TMR cluster groups compared with 1 TMR group. They also reported that further cluster would not provide additional benefits. Kroll et al. (1987) recommended 3 TMR groups including 1 TMR for early lactation ( $<45$ DIM) and 2 TMR for high and low production. Bath and Sosnik (1992) recommended a minimum of 3 TMR groups, but preferred 5 TMR groups, including 1 TMR group for primiparous cows.

It was suggested that production differences in a group should be $15 \%$ or lower (Nocek et al., 1985), which would imply that using a TMR would require at least 3 TMR lactation groups (Coppock et al., 1972). Furthermore, Cabrera and Kalantari (2014) and Kalantari et al. (2015) found a positive relationship between the number of groups and the herd size, concluding that larger herds (e.g., >1,000 cows) could manage 4 TMR groups beyond the early-postpartum cow group, but that smaller herds (e.g., $<1,000$ cows) might be better off with 3 nutritional groups beyond the earlypostpartum cow group. It was clear in Kalantari et al. (2015) that the economic gains rapidly decrease as the number of groups increase. Consequently, a trade-off occurs between gains and number of groups.

A disconnect is present between actual farm nutritional grouping practices and research findings. It is clear that an opportunity exists to improve economic efficiency by increasing the number of nutritional groups in modern dairy farm systems. In general, the recommendation is to have and feed differently 1 TMR early postpartum cow groups and 3 TMR other lactation diet groups; large herds could add 1 TMR for a more nutritional group. Depending on the herd management, farm facilities, and breed, first-lactation cows could also be fed separately.

Size of Feeding Groups. Grant and Albright (2001) listed 9 interacting factors that would determine the optimal group size: (1) feed bunk space and competition for feed, water, and freestalls; (2) social interactions according to group size; (3) space available to the cow; (4) size of holding area and capacity of milking parlor; (5) animal body size and age; (6) body condition; (7) DIM; (8) stall size and condition; and (9) ventilation adequacy. They further proposed, based on Smith et al. (2000), that a good generalization for maximum group size for herringbone or parallel parlors could be 4.5 times the parlor size (e.g., 24 milking units $=108$ cows per group). In fact, feeding management, facilities, and parlor size will impose the maximum size of the group (Grant and Albright, 2001). Group size could be increased with faster cow movement to and from the parlor, continuous availability of feed, and more homogeneous characteristics of cows in the group.

For practical purposes, 2 factors play an important role in determining the group size: (1) the number of lactating cows and (2) the number of available pens. The total number of lactating cows and their lactation stages will determine the number of early postpartum cows that will constitute a separate group and the rest of lactating cows that ideally will constitute 3 other groups. Somehow these numbers need to be matched with the farm facilities. Assuming 4 pens for these animals (same or different sizes), it is likely that cows would be grouped to better fill the capacity of these pens. Normally a compromise is needed. Ideally, pens would be filled using optimal clustering criteria. Modern technologies could help; computerized software could be used to assign cows to groups more efficiently. Also, the use of electronic feeding gates and cow radio frequency identification or similar technologies that allow the feeding of different diets to cows in the same pen could eventually allow farmers to virtually group cows nutritionally and feed them differently without the need of physically moving them. These technologies additionally alleviate potential regrouping social issues.

Frequency of Grouping. Frequency and timing of nutritional grouping events must have critical connotations in its performance because these determine the efficiency of nutritional feeding according to grouping criteria and diet nutrient specifications. However, grouping and regrouping have only been arbitrarily set in nutritional grouping studies.

Some studies used either DIM or milk production thresholds or both in combination (Smith et al., 1978; Cassel et al., 1984; Østergaard et al., 1996), and others a predefined fixed time (McGilliard et al., 1983; Schucker et al., 1988; Williams and Oltenacu, 1992; Cabrera and Kalantari, 2014) for grouping or regrouping events. Some studies regrouped cows only once during a lactation (Smith and Coppock, 1974; Cassel et al., 1984; Østergaard et al., 1996), whereas others regrouped them every few months (Schucker et al., 1988), every month (Williams and Oltenacu, 1992; 
Cabrera and Kalantari, 2014), or even every week (Earleywine, 2001). Smith et al. (1978) and Cassel et al. (1984) defined a first group for at least the first $4 \mathrm{wk}$ of lactation and a minimum milk production threshold before this group could be moved to a second feeding group. Therefore, cows were moved only once during one lactation. This was not so different from separating early postpartum cows in today's dairy farm systems. A conceptual switch toward grouping timing and frequency was introduced by Schucker et al. (1988), which was based on McGilliard et al. (1983); they planned to regroup cows every month by a cluster approach. Schucker et al. (1988) recognized that such an approach was not always practical or feasible under commercial farm situations and then proposed, alternatively, not moving cows until 2 or 3 mo of confirmed recommendations to avoid unnecessary cow shifts. Williams and Oltenacu (1992) evaluated regrouping monthly; this concept has remained predominant in the literature (Cabrera and Kalantari, 2014; Kalantari et al., 2015). Unfortunately, no studies have formally analyzed the timing and frequency of nutritional grouping strategies with respect to performance or economic efficiency. Ideally, the timing and frequency of regrouping should be optimized. Nutritional variability thresholds within and between groups could be used to trigger regrouping at the optimal times.

\section{CONCLUSIONS}

The economic efficiency of dairy farms can be improved substantially by adopting optimal nutritional grouping strategies for lactating cows. These strategies promote more precise feeding with increased productivity and lowered feed costs. Therefore, they promote greater IOFC and an ultimately improved profitability and economic efficiency. A large proportion of US dairy farms do not perform these nutritional groupings or do under suboptimal circumstances. Success or failure is determined by how well nutritional grouping strategies are implemented; ideally, farms might consider implementing 1 TMR nutritional group for earlypostpartum cows and, additionally, 3 TMR nutritional cluster groups for the rest of the lactating cows. One TMR additional nutritional group for first-lactation cows could be optional depending on farm facilities and other management objectives. Once groups of cows are defined, diets should be carefully specified based on the distribution of group nutrient requirements rather than on milk lead factors. Diet nutrient specifications should be dynamically adjusted to group nutrient requirements. Cows properly grouped would not suffer nutrient deficiencies or milk losses because of a change of diets. Social disruptions could occur with group changes depending on the group size and resources available, but, if they occur, they would be short lived and of much less economic importance than the benefits of nutritional grouping. Proper nutritional grouping of lactating cows will improve the overall herd distribution of BCS and, by extension, health, production, and economic efficiency. Nutritional grouping that more precisely matches offered diets to cow nutrient requirements contributes to reduce nutrient excretion and emissions to the environment. Both improved herd health and decreased environmental effects have positive economic implications that should be considered as well. Future studies should optimize group diet formulations and the time and frequency of regrouping. Whole-system, multilactation field studies in modern dairy farm systems combined with simulation projections are recommended to quantify fully the economic efficiency of nutritional grouping in dairy farming.

\section{ACKNOWLEDGMENTS}

Authors are thankful to Randy D. Shaver (University of Wisconsin-Madison) for his professional comments and feedback on an earlier version of this manuscript. Funding for this project was partially provided by the Agriculture and Food Research Initiative Competitive Grant No. 2011-68004-30340 from the USDA National Institute of Food and Agriculture (Washington, DC). This research was also supported by the USDA-University of Wisconsin Hatch Project No. WIS01699 to V. E. Cabrera.

\section{REFERENCES}

Albright, J. L. 1978. Social considerations in grouping cows.Pages $757-$ 779 in Large Dairy Herd Management. C. J. Wilcox and H. H. van Horn, ed. University of Florida Press, Gainesville.

Allen, M. S. 2000. Effect of diet on short-term regulation of feed intake by lactating dairy cattle. J. Dairy Sci. 83:1598-1624.

Allen, M. S. 2008. Time to regroup. Michigan Dairy Review. Accessed Mon, Day, Year. https://www.msu.edu/ mdr/reprints/April08/ timetoreprintapr08.pdf.

Allen, M. S. 2009. Grouping to increase milk yield and decrease feed costs. 20th Annual Tri-State Dairy Nutrition Conference. Ohio State University Press, Columbus.

Arave, C. W., and J. L. Albright. 1981. Cattle behavior. J. Dairy Sci. 64:1318-1329.

Arriaga, H., M. Pinto, S. Calsamiglia, and P. Merino. 2009. Nutritional and management strategies on nitrogen and phosphorus use efficiency of lactating dairy cattle on commercial farms: An environmental perspective. J. Dairy Sci. 92:204-215.

Bath, D. L. and U. Sosnik. 1992. Formulation, delivery and inventory control of cost-effective rations. Pages 709-719 in Large Dairy Herd Management. H. H. Van Horn and C. J. Wilcox, ed. American Dairy Science Association, Champaign, IL.

Bewley, J., R. W. Palmer, and D. B. Jackson-Smith. 2001. Comparison of free-stall barns used by modernized Wisconsin dairies. J. Dairy Sci. 84:528-541. 
Bewley, J. M., and M. M. Schutz. 2008. An interdisciplinary review of body condition scoring for dairy cattle. Prof. Anim. Sci. 24:507529

Botheras, N. A. 2010. The feeding behavior of dairy cows: Considerations to improve cow welfare and productivity. eXtension. Accessed Jul. 19, 2010. http://www.extension.org/pages/25472/the-feedingbehavior-of-dairy-cows:considerations-to-improve-cow-welfareand-productivity\#.Va-HUmCpS1k.

Brakel, W. J., and R. A. Leis. 1976. Impact of social disorganization on behavior, milk yield, and body weight of dairy cows. J. Dairy Sci. 59:716-721.

Cabrera, V. E., F. Contreras, R. D. Shaver, and L. E. Armentano. 2012. Grouping strategies for feeding lactating dairy cattle. Pages 40-44 in Proceedings Four-State Dairy Nutrition and Management Conference. Dubuque, IA, June 13-14, 2012. Wisconsin Agri-business Association, Madison.

Cabrera, V. E., and A. Kalantari. 2014. Strategies to improve economic efficiency of the dairy. WCDS Adv. Dairy Technol. 26:371-382.

Cameron, R. E., P. B. Dyk, T. H. Herdt, J. B. Kaneene, R. Miller, H. F. Bucholtz, J. S. Liesman, M. J. VandeHaar, and R. S. Emery. 1998. Dry cow diet, management and energy balance as risk factors for displaced abomasum in high produced dairy herds. J. Dairy Sci. 81:132-139.

Cassel, E. K., W. G. Merrill, R. A. Milligan, and R. W. Guest. 1984. Evaluation of systems for feeding supplemental concentrate to cows in groups. J. Dairy Sci. 67:560-568.

Clark, P. W., R. E. Rickets, and G. F. Krause. 1977. Effects on milk yield of moving cows from group to group. J. Dairy Sci. 60:769772

Contreras-Govea, F. E., V. E. Cabrera, L. E. Armentano, R. D. Shaver, P. M. Crump, D. K. Beede, and M. J. VandeHaar. 2015. Constraints for nutritional grouping in Wisconsin and Michigan dairy farms. J. Dairy Sci. 98:1336-1344.

Coppock, C. E. 1977. Feeding methods and grouping systems. J. Dairy Sci. 60:1327-1336.

Coppock, C. E., D. L. Bath, and B. Harris. 1981. From feeding to feeding systems. J. Dairy Sci. 64:1230-1249.

Coppock, C. E., C. H. Noller, B. W. Crowl, C. D. McLellon, and C. L. Rhykerd. 1972. Effect of group versus individual feeding of complete rations on feed intake of lactating cows. J. Dairy Sci. $55: 325-327$.

Davenport, D. G., and A. H. Rakes. 1973. Response of dairy cows to two systems of distributing annual total digestible nutrients over the lactation cycle. J. Dairy Sci. 56:465-472.

DeVries, T. J., M. A. G. von Keyserlingk, and D. M. Weary. 2004 Effect of feeding space on the inter-cow distance, aggression, and feeding behavior of free-stall housed lactating dairy cows. J. Dairy Sci. 87:1432-1438.

Earleywine, T. J. 2001. Profitable dietary grain concentrations and grouping strategies in dairy herds. Ph.D. Diss. University of Wisconsin-Madison.

Estevez, I., I. E. Andersen, and E. Naevedal. 2007. Too many, too few: Group size, density and social dynamics in farm animals. Appl. Anim. Behav. Sci. 103:185-204.

Everson, R. A., N. A. Jorgensen, J. W. Crowley, E. L. Jensen, and G. P. Barrington. 1976. Input-output of dairy cows fed a complete ration of a constant or variable forage-to-grain ratio. J. Dairy Sci. 59:1776-1787.

Friend, T. H., C. E. Polan, and M. L. McGilliard. 1977. Free stall and feed bunk requirements relative to behavior, production and individual feed intake in dairy cows. J. Dairy Sci. 60:108-116.

Grant, R. J., and J. L. Albright. 1997. Dry matter intake as affected by cow grouping and behavior. Pages 93-103 in Proc. 58th Minnesota Nutr. Conf., Univ. of Minnesota, Bloomington, MN. University of Minnesota Press, Bloomington.

Grant, R. J., and J. L. Albright. 2001. Effect of animal grouping on feeding behavior and intake of dairy cattle. J. Dairy Sci. 84(E. Suppl.):E156-E163

Hasegawa, N., A. Nishiwaki, K. Sugawara, and I. Ito. 1997. The effects of social exchange between two groups of lactating primiparous heifers on milk production, dominance order, behavior and adrenocortical response. Appl. Anim. Behav. Sci. 51:15-27.

Huzzey, J. M., T. J. DeVries, P. Valois, and M. A. G. von Keyserlingk. 2006. Stocking density and feed barrier design affect the feeding and social behavior of dairy cattle. J. Dairy Sci. 89:126-133.

Jones, G. M., E. E. Wildman, P. Wagner, N. Laming, P. T. Chandler, R. L. Boman, and H. F. Troutt. 1978. Effectiveness of the dairy cattle feed formulation system in developing lactating rations. J. Dairy Sci. 61:1645-1654.

Jonker, J. S., R. A. Kohn, and J. High. 2002. Dairy herd management practices that impact nitrogen utilization efficiency. J. Dairy Sci 85:1218-1226

Jordan, E. R., and R. H. Fourdraine. 1993. Characterization of the management practices of the top milk producing herds in the country. J. Dairy Sci. 76:3247-3256.

Kalantari, A. S., L. E. Armentano, R. D. Shaver, and V. E. Cabrera 2015. Economic impact of nutritional grouping in dairy herds. J. Dairy Sci. 98(Suppl. 2):M279.

Krohn, C. C., and S. P. Konggaard. 1979. Effects of isolating firstlactation cows from older cows. Livest. Prod. Sci. 6:137-146.

Kroll, O., J. B. Owen, and C. J. Whitaker. 1987. Grouping and complete diet composition in relation to parity and potential yield in dairy cows. J. Agric. Sci. 108:281-291.

McGilliard, M. L., J. M. Swisher, and R. E. James. 1983. Grouping lactating cows by nutritional requirements for feeding. J. Dairy Sci. 66:1084

Moseley, J. E., C. E. Coppock, and G. B. Lake. 1976. Abrupt changes in the forage-concentrate ratios of complete feeds fed ad libitum to dairy cows. J. Dairy Sci. 59:1471-1483.

Nocek, J. E., R. L. Steele, and D. G. Braund. 1985. Effects of mixed ration nutrient density on milk of cows transferred from high production group. J. Dairy Sci. 68:133-139.

Nordlund, K., and N. Cook. 2006. Commingling dairy cows: pen moves, stocking density, and health. Pages 36-42 in 39th Proceedings American Association Bovine Practicioners. St. Paul, MN Sep. 20-24, 2006. AABP, Opelika, AL.

Østergaard, S. J., T. Sørensen, J. Hindhede, and A. R. Kristensen. 1996. Technical and economic effects of feeding one vs. multiple total mixed rations estimated by stochastic simulation under different dairy herd and management characteristics. Livest. Prod. Sci. 45:23-33.

Pecsok, S. R., M. L. McGilliard, R. E. James, T. G. Johnson, and J. B. Holter. 1992. Estimating production benefits through simulation of group and individual feeding of dairy cows. J. Dairy Sci 75:1604-1615.

Place, S. E., and F. M. Mitloehner. 2010. Invited review: Contemporary environmental issues: A review of the dairy industry's role in climate change and air quality and the potential of mitigation through improved production efficiency. J. Dairy Sci. 93:34073416

Powell, J. M., D. B. Jackson-Smith, D. F. McCrory, H. Saam, and M. Mariola. 2006. Validation of feed manure data collected on Wisconsin dairy cows. J. Dairy Sci. 89:2268-2278.

Roche, J. R., N. C. Friggens, J. K. Kay, M. W. Fisher, K. J. Stafford, and D. P. Berry. 2009. Invited review: Body condition score and its association with dairy cow productivity, health, and welfare. J. Dairy Sci. 92:5769-5801.

Schucker, B. L., M. L. McGilliard, R. E. James, and C. C. Stallings 1988. A field study of grouping cows by requirements for feeding. J. Dairy Sci. 71:870-878.

Smith, J. F., J. P. Harner, M. J. Brouk, D. V. Armstrong, M. J. Gamroth, and M. J. Meyer. 2000. Relocation and Expansion Planning for Dairy Producers. Publ. MF2424. Kansas State Univ. Coop. Ext. Serv., Manhattan.

Smith, N. E. 1976. Maximizing income over feed costs: evaluation of production response relationships. J. Dairy Sci. 59:1193.

Smith, N. E., and C. E. Coppock. 1974. Group feeding complete feeds to dairy cattle. Page 55 in Proc. Cornell Nutr. Conf., Cornell University, Ithaca, NY. Cornell University Press, Ithaca, NY. 
Smith, N. E., G. R. Ufford, C. E. Coppock, and W. G. Merrill. 1978. One group versus two group system for lactating cows fed complete rations. J. Dairy Sci. 61:1138-1145.

Sniffen, C. J., R. W. Beverly, C. S. Mooney, M. B. Roe, and A. L. Skidmore. 1993. Nutrient requirements versus supply in the dairy cow: strategies to account for variability. J. Dairy Sci. 76:3160-3178.

Sorensen, J. T., E. S. Kristensen, and I. Thysen. 1992. A stochastic model simulating the dairy herd on a PC. Agric. Syst. 39:177-200.

St-Pierre, N. R., and C. S. Thraen. 1999. Animal grouping strategies, sources of variation, and economic factors affecting nutrient balance on dairy farms. J. Anim. Sci. 77(Suppl. 2):72-83.

Stallings, C. C., and M. L. McGilliard. 1984. Leading factors for total mixed ration formulation. J. Dairy Sci. 67:902-907.

Tessmann, N. J., T. R. Dhiman, J. Kleinmans, H. D. Radloff, and L. D. Satter. 1991a. Recombinant bovine somatotropin with lactating cows fed diets differing in energy density. J. Dairy Sci. 74:26332644.

Tessmann, N. J., H. D. Radloff, J. Kleinmans, T. R. Dhiman, and L. D. Satter. 1991b. Milk production response to dietary forage:grain ratio. J. Dairy Sci. 74:2696-2707.
VandeHaar, M. J. 2011. Increasing efficiency of nutrient use to enhance profit and environmental stewardship. In Proc. 22nd Annual Florida Ruminant Nutrition Symposium. Feb. 1-2, 2011, Gainesville, FL. University of Florida Press, Gainesville.

von Keyserlingk, M. A., G. D. Olenick, and D. M. Weary. 2008. Acute behavioral effects of regrouping cows. J. Dairy Sci. 91:1011-1016.

Weiss, W. 2014. Setting nutrient specifications for formulating diets for groups of lactating cows. eXtension. Accessed Jun. 3, 2015. http:// www.extension.org/pages/70124/setting-nutrient-specificationsfor-formulating-diets-for-groups-of-lactating-dairy-cows\#.VMVNMaSXq0.

Wilk, J. C., A. H. Rakes, D. G. Davenport, G. S. Parsons, and R. C. Wells. 1978. Comparison of two systems for group feeding dairy cows. J. Dairy Sci. 61:1429-1434.

Williams, C. B., and P. A. Oltenacu. 1992. Evaluation of criteria used to group lactating cows using a dairy production model. J. Dairy Sci. $75: 155-160$.

Zwald, A., and R. D. Shaver. 2012. Effect of pen change on milk yield by dairy cows in 2 commercial herds. Prof. Anim. Sci. 28:569-572. 